\title{
Resistência de pimentas a nematóides de galha e compatibilidade enxerto/porta-enxerto entre híbridos de pimentão e pimentas
}

\author{
Cristina Duda de Oliveira; Leila T Braz; Jaime M dos Santos; David Ariovaldo Banzatto; Paulo Roberto \\ de Oliveira \\ UNESP-FCAV, Depto. Prod. Vegetal, Rodov. Prof. Paulo Donato Castellane, s/n, 14884-900 Jaboticabal-SP; crisduda@gmail.com
}

\begin{abstract}
RESUMO
Avaliou-se a resistência à Meloidogyne incognita e a compatibilidade de enxertia de treze porta-enxertos de pimenta (nove Capsicum chinense; três $C$. annuum e um C. frutescens) quando enxertados com os híbridos de pimentão-vermelho Rubia R, Margarita e Maximos. O experimento foi conduzido em 2005 na UNESP-FCAV em Jaboticabal-SP. As plantas foram enxertadas por garfagem do tipo fenda simples e, 25 dias após foram avaliadas quanto à percentagem de "pegamento" e, posteriormente, juntamente com plantas sem enxertia, foram transplantadas em casa de vegetação e inoculadas, individualmente, com 5.000 ovos e juvenis de segundo estádio de $M$. incognita. A avaliação da resistência dos porta-enxertos ao nematóide foi feita aos 181 dias após a inoculação, com base no fator de reprodução; a avaliação da compatibilidade enxerto/portaenxerto foi realizada levando em consideração a produtividade e a qualidade dos frutos obtidas em sete colheitas, realizadas entre $113 \mathrm{e}$ 181 dias após o transplante das mudas. Aos 25 dias após a enxertia, para todos os tratamentos, em média, 99,69\% das plantas enxertadas apresentavam-se com "pegamento". Os porta-enxertos C. annuит e $C$. frutescens, ao final do ciclo de cultivo, foram resistentes à $M$. incognita e proporcionaram nas plantas enxertadas, respectivamente, as maiores e menores produtividades e qualidades de frutos, sendo designados de compatíveis e incompatível para enxertia com os híbridos de pimentão-vermelho Rubia R, Margarita e Maximos. 'Maximos' e 'Margarita' quando enxertados apresentaram melhor produtividade e qualidade de frutos do que 'Rubia R'; quando sem enxertia não diferiram em produtividade, havendo destaque para 'Margarita' quanto à qualidade dos frutos.
\end{abstract}

Palavras-chave: Capsicum spp., Meloidogyne spp., enxertia, cultivo protegido.

\begin{abstract}
Hot peppers resistance to root-knot-nematodes and stump/ rootstock compatibility among hot peppers and red pepper hybrids

The resistance to Meloidogyne incognita and propagation compatibility of thirteen pepper rootstocks (nine Capsicum chinense; three $C$. annuum and one $C$. frutescens) were evaluated under Rubia R, Margarita and Maximos red pepper hybrids grafting. The experiment was carried out in 2005, in Jaboticabal, São Paulo State. Plants were cleft and notch grafted and, 25 days later, the pant surviving was evaluated. Later, the grafted plants and plants without stump were transplanted to a greenhouse and inoculated, individually, with 5,000 eggs and infants in the second phase of $M$. incognita. The rootstock resistance to nematodes was evaluated at 181 days after inoculation, based on the reproduction factor. The stump/rootstocks compatibility was evaluated considering yield and quality of fruits obtained through seven harvests, 113 to 181 days after seedling transplant. An average of $99,69 \%$ of surviving plants was obtained, 25 days after grafting date. The $C$. annuum and $C$. frutescens rootstocks were resistant to $M$. incognita at the end of the vegetative cycle and they provided to grafted plants the higher and lower fruit production and quality respectively, being called compatible and non compatible to stump with Rubia R, Margarita, and Maximos red pepper hybrids. 'Maximos' and 'Margarita', when grafted, presented better productivity and fruit quality, than 'Rubia R'; when non-grafted the productivity did not differ among them, prominence having for 'Margarita' about fruit quality.
\end{abstract}

Keywords: Capsicum spp., Meloidogyne spp., grafting, greenhouse.

(Recebido para publicação em 16 de maio de 2008; aceito em 26 de agosto de 2009) (Received in May 16, 2008; accepted in August 26, 2009)

$\mathrm{N}$ o mercado brasileiro, o pimentão é uma das principais hortaliças de frutos e apresenta variação estacional de oferta e preço ao longo do ano. Para aumentar a produtividade, melhorar a qualidade e oferecer pimentão em todas as épocas, a maioria dos produtores, principalmente das regiões Sudeste e Sul do Brasil, têm cultivado-o em ambiente protegido.

Conforme Andriolo et al. (1997) e Fernandes et al. (2002), a maior parte dos cultivos protegidos é realizada no solo. Um dos problemas dos cultivos implantados no solo é a incidência de pragas e patógenos que atacam os sistemas radiculares das plantas, como os nematóides e as podridões de raízes causadas por fungos e bactérias.

As cultivares comerciais de pimentão, disponíveis no mercado brasileiro, apresentam pouca ou nenhuma resistência a patógenos de solo. Até o início da década de 90, em ambiente protegido, no Brasil, a maioria dos produtores de pimentão e de outras olerícolas, para controlar os nematóides realizavam fumigações do solo com brometo de metila.

O brometo de metila, no ano de 1992, foi incluído na lista de substâncias destruidoras do ozônio na atmosfera, e sua eliminação passou a ser objetivo do Protocolo de Montreal, dando prazo para que seja eliminado do mercado até o ano de 2015 (Núcleo de Ecojornalistas do Rio Grande do Sul, 2006; Osava et al., 2006).

No Brasil, de acordo com a Instrução Normativa $n^{\circ} 1$, de 10 de setembro de 2002, assinada em conjunto pelo MAPA, IBAMA e ANVISA, o brometo de me- 
tila não pode ser mais utilizado a partir de janeiro de 2007, antecipando em 09 anos os prazos de eliminação previstos no Protocolo. A única exceção prevista é para os tratamentos quarentenários, que deverão ser proibidos apenas em 2015 (MMA, 2006).

Em substituição ao brometo de metila estão sendo adotadas medidas nãoquímicas de controle de nematóides, como rotação de cultura, pousio, arações profundas e solarização. No entanto, como as mesmas proporcionam retorno econômico a longo prazo, muitas vezes são abandonadas pelos produtores.

$\mathrm{Na}$ região de Reginópolis, importante centro produtor de pimentão em ambiente protegido do Estado de São Paulo, nos últimos cinco anos, como método alternativo ao brometo de metila para reduzir a população de Meloidogyne incognita (Treub) Chitwood e os prejuízos de produtividade da cultura, os produtores têm adotado a técnica da enxertia. Cultivares comerciais de pimentão são enxertadas em porta-enxertos de pimentas resistentes à Phytophthora capsici L. e M. incognita, no caso os híbridos Silver (Sakata) e Snooker (Syngenta).

Lee (2003) cita que na Coréia, em ambiente protegido, aproximadamente $10 \%$ dos cultivos de pimentão-verde são feitos com plantas enxertadas em porta-enxertos de pimentas, e as áreas de cultivo estão aumentando rapidamente, para evitar perdas de produtividade ocasionadas principalmente por $P$. capsici.

No estado de São Paulo, Kobori (1999) estudou o método de enxertia em pimentão, utilizando o híbrido Magali $\mathrm{R}$ enxertado em onze porta-enxertos resistentes a $P$. capsici. Foi observado um pequeno incremento de produção em plantas enxertadas quando comparado com as plantas do híbrido sem enxertia.

Santos \& Goto (2004), ao avaliarem plantas de pimentão enxertadas, concluíram que a técnica da enxertia é viável no controle da murcha de $P$. capsici em ambiente protegido. Todavia, a procura de porta-enxertos com boas características, bem como a investigação de melhores combinações, deve ser uma constante, para, assim, poder otimizar os resultados do emprego da enxertia em hortaliças (Santos, 2001).

Conforme Kobori (1999), a maior dificuldade no emprego da enxertia é a obtenção de bons porta-enxertos, que se adaptem ao ambiente, não interfiram na qualidade dos frutos e mantenham a resistência à doença.

O presente trabalho teve por objetivos avaliar a resistência de pimentas a $M$. incognita e a compatibilidade de enxertia de híbridos de pimentão-vermelho sobre essas pimentas.

\section{MATERIAL E MÉTODOS}

O experimento foi realizado na UNESP, em Jaboticabal, São Paulo, de fevereiro a novembro de 2005, em casa de vegetação, com pé direito de 3,0 $\mathrm{m}$ de altura, coberta com filme de polietileno de $150 \mu \mathrm{m}$ de espessura. $\mathrm{O}$ delineamento experimental utilizado foi blocos casualizados, segundo o esquema fatorial 13 x $3+3$ (13 porta-enxertos de pimenta x 3 enxertos ou, híbridos de pimentãovermelho enxertados +3 híbridos de pimentão-vermelho sem enxertia), com quatro repetições, constituídas por cinco plantas cada.

Dos treze porta-enxertos utilizados, nove foram $C$. chinense, provenientes da área de colonização agrícola de Roraima (C-22; C-23; C-24; C-25; C-27; C-50; C-60; C-61 e C-62), três foram C. annuum (A-3 oriundo de cultivos realizados por produtores da região de Reginópolis-SP; Snooker, híbrido pertencente à empresa de sementes Syngenta Seeds Ltda. e a Linhagem 13, desenvolvida na UNESP-FCAV) e um foi $C$. frutescens (Pimenta-malagueta, obtido também em cultivos na região de Reginópolis-SP), classificados como resistentes à $M$. incognita segundo trabalho realizado por Oliveira et al. (2007).

Os híbridos de pimentão-vermelho utilizados enxertados e sem enxertia foram: Rubia R (Sakata Seed Sudamérica), Margarita (Rogers Syngenta Seeds) e Maximos (Clause). Todos estes híbridos são suscetíveis a $M$. incognita (Oliveira et al., 2007).

As mudas foram produzidas em bandejas de poliestireno expandido com 128 células, utilizando substrato Plantmax ${ }^{\circledR}$. Os porta-enxertos C. chinense, Pimentamalagueta, A-3 e dos três híbridos de pimentão-vermelho sem enxertia foram semeados em 10 de fevereiro; a semeadura dos porta-enxertos Snooker e Linhagem 13 e, dos três híbridos cujas mudas foram utilizadas como enxertos foi feita em 12 de março. A razão da semeadura dos porta-enxertos em datas distintas foi devido à diferença na velocidade de germinação e crescimento dos mesmos, conforme análise prévia.

Para disponibilizar maior volume de substrato e promover maior crescimento e desenvolvimento das mudas dos portaenxertos e dos híbridos sem enxertia, as mesmas foram transplantadas em copos descartáveis de $200 \mathrm{~mL}$, contendo substrato Plantmax ${ }^{\circledR}$, aos 55 e 25 dias após a semeadura (DAS), respectivamente.

Aos 70 DAS dos porta-enxertos $C$. chinense, Pimenta-malagueta e A-3 e, 40 DAS dos porta-enxertos 'Snooker' e Linhagem 13 e dos enxertos, 16 plantas por repetição foram enxertadas pelo método fenda simples, que é o mais utilizado para solanáceas (Goto et al., 2003b).

Para ajudar no processo de "pegamento" das plantas, no sentido da abertura do corte do porta-enxerto, de maneira a envolver o ponto de junção das plantas enxertadas, foram colocados clipes plásticos próprios para enxertia de Capsicum, sendo as plantas enxertadas, em seguida, acondicionadas em câmara úmida do tipo "flouting".

A câmara úmida foi construída no interior de uma casa da vegetação e era formada por um túnel baixo de 12,00 m de comprimento, por 1,20 m de largura, com altura de $0,70 \mathrm{~m}$ na parte central, coberto com filme transparente ultra violeta e com sombrite $50 \%$, que comportava em sua base um filme de polietileno preto que continha uma lamina d'água de 0,02 a $0,03 \mathrm{~m}$ de altura.

O filme de polietileno preto foi fixado em uma grade de aço de 12,00 $\mathrm{m}$ de comprimento; 1,10 m de largura e 0,08 $\mathrm{m}$ de altura, compartimentada transversalmente a cada $0,07 \mathrm{~m}$, de modo a permitir a acomodação de cada repetição dos tratamentos separadamente.

Nos primeiros 10 dias após a enxer- 
tia (DAE), 25\% da câmara úmida era aberta de manhã pelo período de uma hora, sendo em seqüência fechada. A partir dos 10 DAS a câmara passou a não ser fechada e, a cada 3 dias abriamse mais $25 \%$ da mesma, promovendo a aclimatação das plantas enxertadas e melhoria da cicatrização do ponto de enxertia.

Aos 25 (DAE) os clipes foram retirados das plantas enxertadas e procedeu-se a avaliação da percentagem de "pegamento" e o transplante em casa de vegetação, no espaçamento de 1,20 m entre as linhas por $0,40 \mathrm{~m}$ entre as plantas, de cinco plantas por repetição.

A casa de vegetação utilizada continha $M$. incognita no solo mas, para garantir a presença do nematóide em toda a área e poder estudar a resistência dos porta-enxertos no final do ciclo de cultivo, no ato do transplante das mudas, inocularam-se em cada sistema radical $10 \mathrm{~mL}$ de suspensão, contendo 500 ovos e juvenis de segundo estádio/mL de $M$. incognita.

O inóculo aplicado nas mudas foi preparado segundo a técnica de Hussey \& Barker (1973), com as modificações introduzidas por Bonetti \& Ferraz (1981), a partir de raízes de plantas de tomateiro infectadas pelo nematóide, mantidas em vasos de $3 \mathrm{~L}$ contendo substrato previamente tratado, em casa de vegetação.

O solo da casa de vegetação foi preparado com rotoencanteiradora, dez dias antes do transplante. No momento do preparo do solo, com base nos resultados da análise do solo e de acordo com a recomendação de adubação para a cultura feita por Trani et al. (1997), foram incorporados ao mesmo 88,89 $\mathrm{g} / \mathrm{m}^{2}$ de superfosfato simples; 20,69 g/ $\mathrm{m}^{2}$ de cloreto de potássio; $2,89 \mathrm{~g} / \mathrm{m}^{2}$ de uréia; $13,64 \mathrm{~g} / \mathrm{m}^{2}$ de sulfato de amônio, e $0,91 \mathrm{~g} / \mathrm{m}^{2}$ de bórax, de modo a fornecer ao solo $16 ; 12 ; 4 ; 3$ e $0,1 \mathrm{~g} / \mathrm{m}^{2}$ de fósforo, potássio, nitrogênio, enxofre e boro, respectivamente.

Durante a condução do experimento foram realizadas adubações em cobertura e foliar a cada quinze dias. Em cada adubação de cobertura foram aplicados $0,96 \mathrm{~g}$ de nitrogênio e de potássio por planta, cujas fontes fornecedoras dos nutrientes foram a uréia e o cloreto de potássio (Trani et al., 1997). As adubações foliares foram feitas com produtos à base de micro e macronutrientes. Os tratamentos fitossanitários foram realizados de acordo com as necessidades da cultura.

As plantas foram tutoradas no sistema de cultivo em "V", com quatro hastes. Os brotos laterais, que surgiram abaixo da primeira bifurcação, foram eliminados ao longo do ciclo da cultura, e a flor, que surgiu na primeira bifurcação, foi retirada na data da antese.

O sistema de irrigação adotado foi por gotejamento. De acordo com Batal \& Smittle (1981), a cultura do pimentão apresenta elevada sensibilidade a variações na disponibilidade de água no solo, e segundo Klar (2000) a irrigação por gotejamento, por ser manejada com baixa vazão e pressão, permite a manutenção de elevada disponibilidade de água no solo durante todo o ciclo da cultura, o que é o ideal (Filgueira, 2003).

Foi utilizada a cobertura do solo com polietileno negro de modo a auxiliar na redução da evaporação da água do solo para a atmosfera, promover aproveitamento da água disponível pelas plantas e controlar as plantas daninhas entre as plantas (Buriol et al., 1996). O controle de plantas daninhas entre as linhas, quando necessário, foi feito através de capinas.

Foram realizadas sete colheitas, aos $113 ; 121 ; 133 ; 141 ; 153 ; 170$ e 181 dias após o transplante (DAT), quando foram colhidos, em três plantas por parcela, os frutos que apresentavam $70 \%$ ou mais de coloração vermelha.

Nas colheitas, avaliou-se a produtividade de frutos comerciais, em número e massa fresca de frutos $/ \mathrm{m}^{2}$ e a massa fresca média do fruto comercial. Os dez primeiros frutos comerciais colhidos foram também avaliados quanto ao comprimento, diâmetro e espessura da polpa. Foram considerados como fruto comercial os de comprimento igual ou superior a 4,0 cm e sem defeitos graves (fruto com podridão, murcho, queimado ou com dano não cicatrizado). As médias de produtividade e qualidade dos frutos foram submetidos à análise de variância e ao teste de Tukey, no nível de 5\% de probabilidade, sendo os dados de número de frutos comerciais/ $\mathrm{m}^{2}$ transformados em $\sqrt{\mathrm{x}}$.

Aos 181 DAT, além de ser feita a última colheita de frutos, foram coletados cinco sistemas radiculares de cada combinação porta-enxerto $\mathrm{x}$ enxerto $\mathrm{e}$ dos híbridos sem enxertia e os mesmos foram avaliados quanto à resistência a M. incognita.

A avaliação da resistência foi realizada segundo Cook \& Evans (1987), com base na determinação do valor médio do fator de reprodução (FR) para cada sistema radicular, com posterior cálculo da média. Os sistemas radiculares que apresentaram $\mathrm{FR}<1$ foram considerados resistentes à $M$. incognita e os que apresentaram $\mathrm{FR}>1$ foram considerados suscetíveis.

Para a determinação do valor médio do fator de reprodução (FR) para cada sistema radicular, de acordo com a técnica de Hussey \& Barker (1973), com as modificações introduzidas por Bonetti \& Ferraz (1981), foi preparada uma suspensão de ovos e juvenis de diferentes estádios de desenvolvimento do nematóide.

\section{RESULTADOS E DISCUSSÃO}

Aos 25 DAE, ao retirar os clipes, observou-se que as plantas enxertadas estavam com excelente cicatrização no ponto de enxertia e a percentagem de plantas enxertadas com "pegamento" foi em média de 99,69\% para todos os tratamentos, o que equivale a 15,95 plantas/ repetição. Santos (2001), no Brasil, ao enxertar os híbridos comerciais de pimentão Elisa, Magali-R e Margarita com os porta-enxertos de pimenta AF-2638 e AF-2640, resistentes a Phytophthora capsici e $M$. incognita, verificaram de 88 a 100\% de "pegamento" de plantas e, Choe et al. (1985), na Coréia, ao enxertarem a cultivar comercial de pimentão 'Bulam-House-Putgochu' com linhagens e cultivares de pimentão resistentes a $P$. capsici, verificaram, em média, 93\% de "pegamento" de plantas.

Melo et al. (2005) na tentativa de adaptar a metodologia de enxertia de pimentão em pimentas, utilizando como porta-enxerto a Linhagem CNPH 148 
Tabela 1. Fator de reprodução (FR) de Meloidogyne incognita, em plantas de híbridos de pimentão-vermelho enxertadas (E) em porta-enxertos de pimentas (PE) e de plantas de híbridos sem enxertia (HSE), aos 181 dias após a inoculação do nematóide. (Meloidogyne incognita reproduction factor (FR) in red pepper hybrids grafting plants hot peppers rootstocks and non-grafted hybrids plants, 181 days after nematode inoculation). Jaboticabal, UNESP-FCAV, 2005.

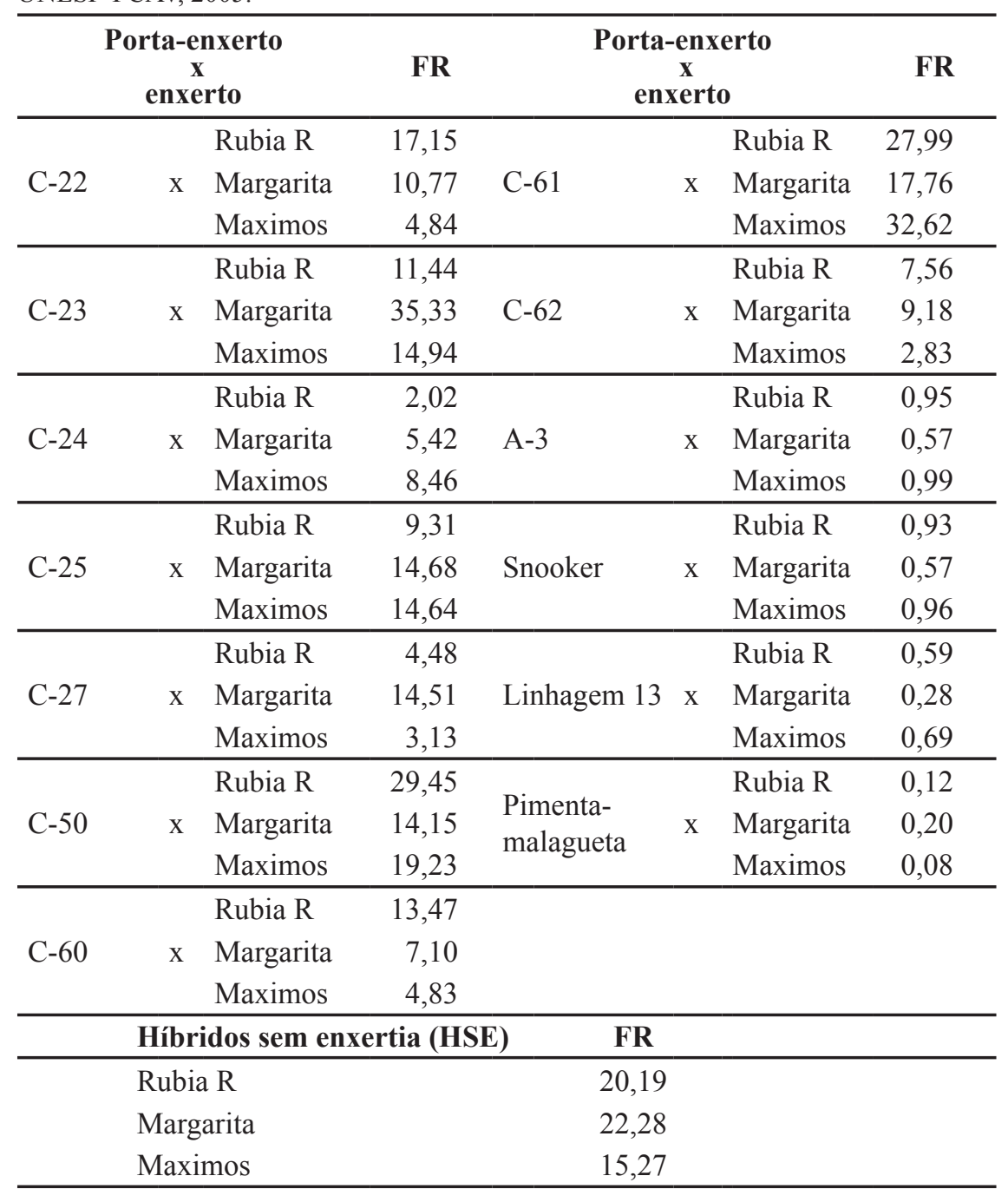

(C. annuum) resistente a $P$. capsici, para os genótipos de pimenta C. baccatum, $C$. chinense e $C$. frutescens, obtiveram de 60 a 100\% de "pegamento" de plantas.

$\mathrm{Na}$ casa de vegetação, aos 181 dias após o transplante das mudas e a inoculação de $M$. incognita, ou seja após o período de quatro ciclos reprodutivos do nematóide, os três híbridos de pimentão sem enxertia e os nove porta-enxertos $C$. chinense foram suscetíveis ao nematóide (FR $>1$ ); os porta-enxertos $C$. annuum ou $C$. frutescens apresentaram $\mathrm{FR}<1$ e foram considerados resistentes a $M$. incognita (Tabela 1).

A perda da resistência à $M$. incognita dos porta-enxertos $C$. chinense, do solo, em média, $9,41^{\circ} \mathrm{C}$ inferior à do ar (Figura 1) também pode ter proporcionado condições favoráveis ao desenvolvimento do nematóide nos porta-enxertos $C$. chinense, tornando-os suscetíveis ao final do ciclo de cultivo.

De acordo com Yamakawa (1982), quando um determinado porta-enxerto é utilizado em solos altamente infestados por determinado patógeno ou em condições desfavoráveis ao seu desenvolvimento, pode tornar-se suscetível. Thies \& Fery (2006), ao avaliarem, em solo com temperaturas controladas de $24 ; 28$ e $32^{\circ} \mathrm{C}$, a reprodução de $M$. incognita em genótipos de pimentão resistentes e suscetíveis, inoculados com 5.000 ovos, verificaram que, com a elevação da temperatura, todos os genótipos foram suscetíveis. Porém, os conhecidamente resistentes expressaram menor população de $M$. incognita em relação aos suscetíveis.

Para as características de produtividade e qualidade dos frutos (Tabela 2), não houve interação significativa entre as médias dos porta-enxertos de pimenta $(\mathrm{PE})$ e enxertos (E). Todavia, ocorreu efeito significativo tanto para portaenxertos de pimenta (PE) quanto para enxertos (E) para todas as características de produtividade e qualidade de frutos, exceto quanto ao número de frutos comerciais $/ \mathrm{m}^{2}$, para enxertos $(\mathrm{E})$.

Entre os híbridos sem enxertia (HSE) ocorreram diferenças significativas para as características massa fresca média do fruto, comprimento e diâmetro médio de frutos comerciais (Tabela 2). Na comparação HSE vs (PE x E) foram detectadas diferenças apenas para massa fresca por fruto comercial e comprimento médio de frutos comerciais, nos quais os híbridos sem enxertia contiveram, respectivamente, $37,75 \mathrm{~g}$ e $0,96 \mathrm{~cm}$ a mais em relação ao grupo do fatorial.

Kobori (1999), ao avaliar quinze tratamentos constituídos por onze portaenxertos híbridos, duas testemunhas porta-enxertos suscetíveis ('Magali R' $\mathrm{e}$ 'Ikeda'), uma testemunha porta-enxerto resistente (SCM-334) e uma testemunha suscetível pé-franco ('Magali R'), não observou diferença significativa entre os tratamentos para as médias do número e massa de frutos colhidos aos 112; 126 e 154 DAE. 
Tabela 2. Número (NFC) e massa fresca (MFC), média de massa fresca por fruto (MFFC), comprimento médio (CF), diâmetro médio (DF) e espessura média da polpa (EPF) de frutos comerciais de pimentão $/ \mathrm{m}^{2}$, de plantas enxertadas em pimentas e sem enxertia. (number (NFC), fresh mass (MFC), average fresh mass per fruit (MFFC), average length (CF), average diameter (DF) and average pulp thickness (EPF) of pepper commercial fruits $/ \mathrm{m}^{2}$, hot peppers grafted and non-grafted plants). Jaboticabal, UNESP-FCAV, 2005.

\begin{tabular}{|c|c|c|c|c|c|c|c|}
\hline \multirow{2}{*}{ Porta-enxertos } & \multicolumn{2}{|c|}{$\mathrm{NFC} / \mathrm{m}^{2}$} & \multirow{2}{*}{$\begin{array}{c}\text { MFC } \\
\left(\mathrm{kg} / \mathrm{m}^{2}\right)\end{array}$} & \multirow{2}{*}{$\begin{array}{c}\text { MFFC } \\
\text { (g) }\end{array}$} & \multirow{2}{*}{$\begin{array}{c}\text { CF } \\
(\mathrm{cm})\end{array}$} & \multirow{2}{*}{$\begin{array}{c}\text { DF } \\
(\mathrm{mm})\end{array}$} & \multirow{2}{*}{$\begin{array}{c}\text { EPF } \\
(\mathrm{mm})\end{array}$} \\
\hline & $(*)$ & $(* *)$ & & & & & \\
\hline $\mathrm{C}-22$ & 13,47 & $3,71 \mathrm{bcd}$ & $1,99 \mathrm{abc}$ & $147,76 \mathrm{a}$ & $12,06 \mathrm{a}$ & $64,10 \mathrm{~b}$ & $5,18 \mathrm{abc}$ \\
\hline $\mathrm{C}-23$ & 12,07 & $3,47 \mathrm{~cd}$ & $1,59 \mathrm{c}$ & $131,67 \mathrm{a}$ & $11,03 \mathrm{a}$ & $65,95 \mathrm{ab}$ & $4,82 \mathrm{bc}$ \\
\hline $\mathrm{C}-24$ & 16,89 & $4,22 \mathrm{abc}$ & $2,49 \mathrm{ab}$ & $147,41 \mathrm{a}$ & $11,73 \mathrm{a}$ & $71,34 \mathrm{ab}$ & $5,37 \mathrm{abc}$ \\
\hline $\mathrm{C}-25$ & 13,68 & 3,79 abcd & $1,73 \mathrm{bc}$ & $126,45 \mathrm{a}$ & $11,57 \mathrm{a}$ & $67,27 \mathrm{ab}$ & $5,08 \mathrm{abc}$ \\
\hline $\mathrm{C}-27$ & 10,50 & $3,30 \mathrm{~d}$ & $1,80 \mathrm{bc}$ & $171,37 \mathrm{a}$ & $11,07 \mathrm{a}$ & $66,99 \mathrm{ab}$ & $4,77 \mathrm{c}$ \\
\hline$C-50$ & 14,40 & 3,79 abcd & $1,81 \mathrm{bc}$ & $125,68 \mathrm{a}$ & $10,90 \mathrm{a}$ & $69,56 \mathrm{ab}$ & $5,06 \mathrm{abc}$ \\
\hline$C-60$ & 12,54 & $3,67 \mathrm{bcd}$ & $1,76 \mathrm{bc}$ & $140,40 \mathrm{a}$ & $11,21 \mathrm{a}$ & $68,14 \mathrm{ab}$ & $5,17 \mathrm{abc}$ \\
\hline C-61 & 15,54 & 3,93 abcd & $2,56 \mathrm{ab}$ & $164,71 \mathrm{a}$ & $12,62 \mathrm{a}$ & $75,74 \mathrm{a}$ & $5,57 \mathrm{a}$ \\
\hline$C-62$ & 13,55 & $3,76 \mathrm{abcd}$ & $2,06 \mathrm{abc}$ & $152,01 \mathrm{a}$ & $11,82 \mathrm{a}$ & $69,98 \mathrm{ab}$ & $5,24 \mathrm{abc}$ \\
\hline A-3 & 20,67 & $4,54 \mathrm{a}$ & $2,60 \mathrm{ab}$ & $125,76 \mathrm{a}$ & $11,73 \mathrm{a}$ & $68,80 \mathrm{ab}$ & $5,23 \mathrm{abc}$ \\
\hline Snooker & 19,71 & $4,45 \mathrm{ab}$ & $2,74 \mathrm{a}$ & $138,99 \mathrm{a}$ & $12,40 \mathrm{a}$ & $67,65 \mathrm{ab}$ & $5,52 \mathrm{ab}$ \\
\hline Linhagem 13 & 17,77 & $4,20 \mathrm{abc}$ & $2,81 \mathrm{a}$ & $158,17 \mathrm{a}$ & $12,46 \mathrm{a}$ & $71,64 a b$ & $5,41 \mathrm{abc}$ \\
\hline Pimenta-malagueta & 5,48 & $2,42 \mathrm{e}$ & $0,27 \mathrm{~d}$ & $49,24 \mathrm{~b}$ & $6,48 \mathrm{~b}$ & $51,03 \mathrm{c}$ & $3,47 \mathrm{~d}$ \\
\hline Média & 14,33 & 3,79 & 2,02 & 136,89 & 11,31 & 67,55 & 5,07 \\
\hline \multirow{2}{*}{ Enxertos } & \multicolumn{2}{|c|}{$\mathrm{NFC} / \mathrm{m}^{2}$} & MFC (kg/ & MFFC (o) & $C F(\mathrm{~cm})$ & DF (mm) & FPF $(\mathrm{mm})$ \\
\hline & $(*)$ & $(* *)$ & $\left.\mathbf{m}^{2}\right)$ & MFFC (g) & $C F(\mathrm{~cm})$ & OF (mm) & EPF (mm) \\
\hline Rubia R & 14,71 & 3,75 & $1,81 \mathrm{~b}$ & $123,03 \mathrm{~b}$ & $10,72 \mathrm{~b}$ & $65,54 \mathrm{~b}$ & $4,89 \mathrm{~b}$ \\
\hline Margarita & 13,67 & 3,66 & $2,05 \mathrm{ab}$ & $150,01 \mathrm{a}$ & $11,82 \mathrm{a}$ & $69,15 \mathrm{a}$ & $5,01 \mathrm{~b}$ \\
\hline Maximos & 15,91 & 3,94 & $2,19 \mathrm{a}$ & $137,65 \mathrm{ab}$ & $11,40 \mathrm{a}$ & $67,97 \mathrm{ab}$ & $5,30 \mathrm{a}$ \\
\hline Média & 14,76 & 3,78 & 2,02 & 136,90 & 11,31 & 67,55 & 5,07 \\
\hline \multirow{2}{*}{ Híbridos sem enxertia } & \multicolumn{2}{|c|}{$\mathrm{NFC} / \mathrm{m}^{2}$} & \multirow{2}{*}{$\begin{array}{c}\text { MFC (kg/ } \\
\left.\mathrm{m}^{2}\right)\end{array}$} & \multirow{2}{*}{$\operatorname{MFFC}(g)$} & \multirow{2}{*}{$\mathrm{CF}(\mathrm{cm})$} & \multirow{2}{*}{$\mathrm{DF}(\mathrm{mm})$} & \multirow{2}{*}{$\operatorname{EPF}(\mathbf{m m})$} \\
\hline & $(*)$ & $(* *)$ & & & & & \\
\hline Rubia R & 15,95 & 3,98 & 2,76 & $173,01 \mathrm{ab}$ & $12,27 \mathrm{ab}$ & $70,10 \mathrm{ab}$ & 5,31 \\
\hline Margarita & 10,76 & 3,69 & 2,33 & $216,58 \mathrm{a}$ & $13,71 \mathrm{a}$ & $79,03 \mathrm{a}$ & 5,25 \\
\hline Maximos & 15,03 & 3,94 & 2,02 & $134,37 \mathrm{~b}$ & $10,83 \mathrm{~b}$ & $63,54 \mathrm{~b}$ & 5,18 \\
\hline Média & 13,91 & 3,87 & 2,37 & 174,65 & 12,27 & 70,89 & 5,25 \\
\hline Teste F (HSE vs fatorial) & - & $0,22 \mathrm{~ns}$ & $3,31 \mathrm{~ns}$ & $11,75 * *$ & $6,43 *$ & $2,34 \mathrm{~ns}$ & $1,43 \mathrm{~ns}$ \\
\hline Teste F (HSE) & - & $0,27 \mathrm{~ns}$ & $1,33 \mathrm{~ns}$ & $5,00 * *$ & $5,22 * *$ & $4,56 *$ & $0,07 \mathrm{~ns}$ \\
\hline Teste F (PE) & - & $10,40 * *$ & $13,20 * *$ & $8,10 * *$ & $18,29 * *$ & $7,50 * *$ & $13,43 * *$ \\
\hline Teste F (E) & - & $2,92 \mathrm{~ns}$ & $4,45 *$ & $7,01 * *$ & $10,06 * *$ & $3,33 *$ & $9,07 * *$ \\
\hline Teste F (PE x E) & - & $1,28 \mathrm{~ns}$ & $0,81 \mathrm{~ns}$ & $0,57 \mathrm{~ns}$ & $1,09 \mathrm{~ns}$ & $1,51 \mathrm{~ns}$ & $0,87 \mathrm{~ns}$ \\
\hline $\mathrm{CV}(\%)$ & - & 15,54 & 31,58 & 26,34 & 11,07 & 10,74 & 9,95 \\
\hline
\end{tabular}

Médias seguidas da mesma letra nas colunas não diferem significativamente entre si pelo teste de Tukey, $\mathrm{p}<0,05$. $(*)$ Dados originais; $(* *)$ Dados transformados em $\sqrt{x}$, para a análise estatística (means followed by the same letter in the column did not differ from each other by the Tukey test, $\mathrm{p}<0.05$. (*) Original data; $(* *)$ Raw data transformed to $\sqrt{\mathrm{x}}$, f or analysis).

Em trabalho realizado por Santos \& Goto (2004), os híbridos de pimentão Magali R, Margarita e Elisa, enxertados nos porta-enxertos AF-2638 e AF-2640 e sem enxertia, mostraram diferenças de produtividade em relação à massa fresca de frutos comerciais. Santos \& Goto (2005) ao avaliarem os híbridos de pimentão Rubia R e Margarita sem enxertia e enxertados nos dois portaenxertos utilizados por Santos \& Goto (2004), não registraram diferenças produtivas, tanto em massa como em número de frutos.

Os resultados do presente trabalho e de pesquisas mencionadas mostram que a resposta produtiva dos híbridos de pimentão-vermelho à enxertia é dependente tanto do porta-enxerto utilizado como das condições ambientais em que as plantas são conduzidas.

O porta-enxerto A-3 promoveu nas plantas enxertadas maior produtividade em número de frutos comerciais $/ \mathrm{m}^{2}$ 


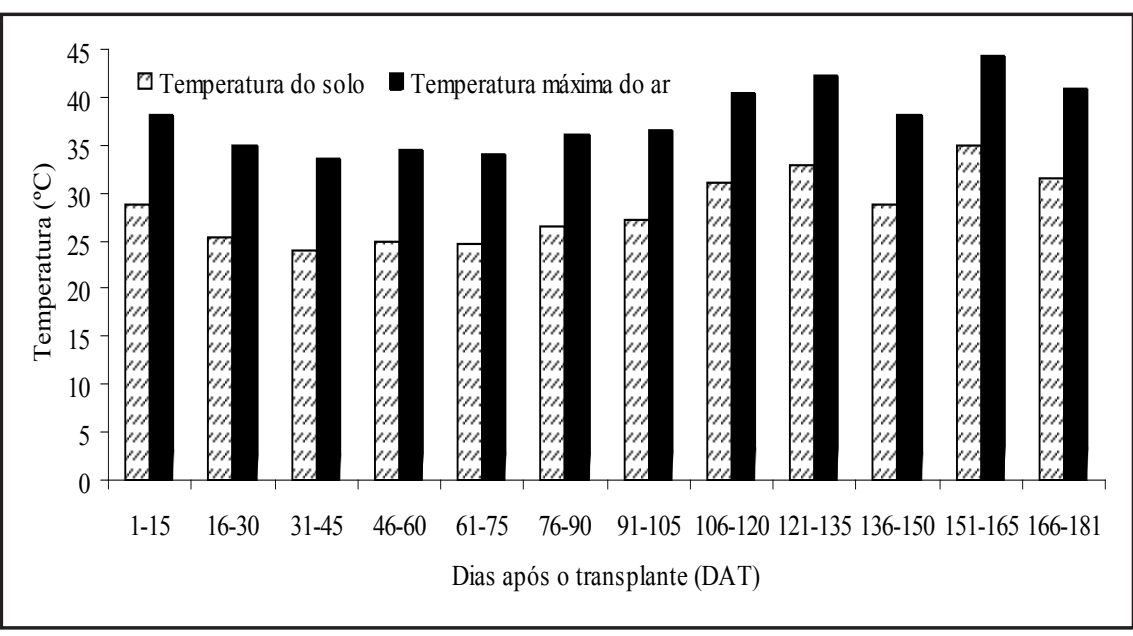

Figura 1. Médias quinzenais de temperaturas do solo $\left({ }^{\circ} \mathrm{C}\right)$ e temperaturas máximas do ar $\left({ }^{\circ} \mathrm{C}\right)$, ocorridas dentro da casa de vegetação durante a condução do experimento (average soil temperatures $\left({ }^{\circ} \mathrm{C}\right)$ and maximum air temperatures $\left({ }^{\circ} \mathrm{C}\right)$ every fifteen days, inside the greenhouse during the research). Jaboticabal, UNESP-FCAV, 2005.

diferindo dos porta-enxertos Pimentamalagueta; C-27; C-23; C-60 e C-22, que apresentaram o menor número de frutos comerciais $/ \mathrm{m}^{2}$ (Tabela 2).

Para a massa fresca de frutos comerciais $/ \mathrm{m}^{2}$ (Tabela 2), as plantas de pimentão-vermelho enxertadas com os porta-enxertos Linhagem 13 e 'Snooker' se destacaram com superior produtividade, mas, essas não foram maiores que as obtidas com os porta-enxertos A-3; C-61; C-24; C-62 e C-22, respectivamente. Independentemente do híbrido de pimentão utilizado, as plantas enxertadas no porta-enxerto Pimentamalagueta foram as menos produtivas, tanto em número como em massa de frutos comerciais $/ \mathrm{m}^{2}$.

O porta-enxerto Pimenta-malagueta também foi responsável pela produção de frutos de menor comprimento, diâmetro e espessura da polpa, estando estes baixos valores relacionados com a baixa produtividade registrada (Tabela 2).

O porta-enxerto C-61 promoveu os maiores diâmetros e espessuras de polpa dos frutos, diferindo dos diâmetros obtidos para frutos provenientes das plantas enxertadas com os portaenxertos Pimenta-malagueta e C-22 e das espessuras de polpas verificadas para os frutos de plantas enxertadas com os porta-enxertos Pimenta-malagueta; C-27 e C-23 (Tabela 2).

Miguel (1997) citou que o pimentão pode ser enxertado somente sobre plantas do seu mesmo gênero, e Goto et al. (2003a) descrevem que a enxertia do pimentão só é possível com plantas da mesma espécie.

Admite-se que a maioria dos portaenxertos da espécie $C$. chinense, em relação aos da $C$. annuum, mostraram uma tendência de menor compatibilidade para enxertia com os híbridos de pimentão. Todavia, essa tendência pode estar relacionada à não-manutenção da resistência dos porta-enxertos $C$. chinense a $M$. incognita aos 181 DAI (Figura 1) e não à menor compatibilidade de enxertia dos mesmos com os híbridos de pimentão utilizados, sendo indispensáveis outros estudos de compatibilidade de enxertia dos porta-enxertos

\section{C. chinense $\operatorname{com} C$. annuum.}

Entre os enxertos (Tabela 2), independentemente do porta-enxerto utilizado, 'Rubia R' apresentou a menor massa fresca comercial de frutos $/ \mathrm{m}^{2}$, bem como as menores massas médias, comprimento e diâmetro de frutos comerciais, não diferindo de 'Margarita' quanto à massa fresca de frutos comerciais $/ \mathrm{m}^{2}$ e de 'Maximos' com relação à massa fresca e diâmetro por fruto comercial. Quanto à espessura da polpa (Tabela 2), o enxerto 'Maximos' se destacou com superior espessura, justificando a maior produtividade em massa $/ \mathrm{m}^{2}$, obtida para o mesmo (Tabela 2).

Quando foram analisados os híbridos sem enxertia, observou-se que 'Marga- rita' apresentou massa, comprimento e diâmetro superiores por fruto comercial, e 'Maximos' as menores, e ambos não diferiram de 'Rubia R' (Tabela 2).

As plantas enxertadas, aos 25 dias após a enxertia, apresentaram excelente percentagem de "pegamento" $(99,69 \%)$, independentemente da combinação porta-enxerto $\mathrm{x}$ enxerto utilizada.

Os porta-enxertos $C$. annuum e $C$. frutescens ao final do ciclo de cultivo foram resistentes à $M$. incognita e proporcionaram nas plantas enxertadas, respectivamente, as maiores e menores produtividades e qualidades de frutos, sendo designados de compatíveis e incompatível para enxertia com os híbridos de pimentão-vermelho Rubia R, Margarita e Maximos.

'Maximos' e 'Margarita' quando enxertados, em relação a 'Rubia R', apresentaram melhor produtividade $\mathrm{e}$ qualidade de frutos; quando sem enxertia não diferiram em produtividade, e 'Margarita' destacou-se quanto à qualidade dos frutos.

\section{AGRADECIMENTOS}

À FAPESP, pelo auxílio financeiro ao projeto, Processo no 2003/13666-5; à CAPES, pela concessão de bolsa de doutorado para a primeira autora, e aos produtores de pimentão da região de Reginópolis-SP, por cederem plantas de pimentão com M. incognita, para serem usadas como inóculo.

\section{REFERÊNCIAS}

ANDRIOLO JL; DUARTE TS; LUDKE L; SKREBSSKY EC. 1997. Crescimento e desenvolvimento do tomateiro cultivado em substrato com fertirrigação. Horticultura Brasileira 15: 28-32.

BATAL GPA; SMITTLE DA. 1981. Response of bell pepper to irrigation, nitrogen and plant population. Journal of the American Society for Horticultural Science 106: 259-262.

BONETTI SI; FERRAZ S. 1981. Modificações do método de Hussey \& Barker para extração de ovos de Meloidogyne incognita de raízes de cafeeiro. Fitopatologia Brasileira 6: 553.

BURIOL G; STRECK NA; SCHNEIDER FM; HELDWEIN AB. 1996. Temperature and moisture regime of a soil covered with transparent mulches. Revista Brasileira de Agrometeorologia 4: 1-6.

CHOE JS.; KANG KY; AHN JK; UM YC; BAN 
CD. 1985.Control of Phytophthora root rot (Phytophthora capsici) of green pepper under plastic house by grafting of resistant rootstocks. Research Reports of the Rural Development Administration Horticulture 27: 6-11.

COOK R; EVANS K. 1987. Resistance and tolerance. In: BROWN RH; KERRY BR (eds). Principles and practice of nematode control in crops. New York: Academic Press. p. 179-231.

FERNANDES C; ARAÚJO JAC; CORÁ JE. 2002. Impacto de quatro substratos e parcelamento da fertirrigação na produção de tomate sob cultivo protegido. Horticultura Brasileira 20: 559-563.

FILGUEIRA FAR. 2003. Novo manual de olericultura: agrotecnologia moderna na produção e comercialização de hortaliças. Viçosa: UFV. 412p.

GOTO R; CAÑIZARES KAL; STRIPARI PC. 2003a. Fatores que influenciam a enxertia. In: GOTO R; SANTOS HS; CAÑIZARES KAL (orgs). Enxertia em hortaliças. São Paulo: UNESP. p. 25-31.

GOTO R; KOBORI RF; SANTOS HS; CAÑIZARES KAL. 2003b. Metodologia de enxertia. In: GOTO R; SANTOS HS; CAÑIZARES KAL (orgs). Enxertia em hortaliças. São Paulo: UNESP. p. 57-67.

HUSSEY RS; BARKER KR. 1973. A comparison of methods of collecting inocula of Meloidogyne spp. including a new technique. Plant Disease Report 57: 1025-1028.

KLAR AE. 2000. Critérios para escolha do método de irrigação. Irriga 5: 52-82.

KOBORI RF. 1999. Controle da murcha de Fitóftora (Phytophthora capsici) em pimentão (Capsicum annuum L.) através da enxertia. Botucatu: UNESP-FCA. 138p (Tese doutorado).

LEE JM. 2003. Advances in vegetable grafting. Chronica Horticulturae, 43: 13-19.

MELO RAC.; RIBEIRO CSC; PORTO IS. 2005. Uso de enxertia em Capsicum spp. como método alternativo de controle à murcha-defitóftora. IN: CONGRESSO BRASILEIRO DE OLERICULTURA, 45. Resumos expandidos ... Horticultura Brasileira, Brasília, 23. Suplemento 2. CD-ROM.

MIGUEL AG. 1997. Injerto en hortalizas. Valencia: Conselleria de agricultura, pesca y alimentación, 88p.

MMA - Ministerio do Meio Ambiente. 2006, 30 de julho. Brometo de metila. Disponível em http:// www.mma.gov.br/sqa/ozonio/?submenu=6

Núcleo de Ecojornalistas do Rio Grande do Sul. 2006. 30 de julho. ONU faz acordo para eliminar pesticida. Disponível em http:// www.ecoagencia. com.br/index.php?option= content\&task=view\&id=1546\&Itemid=2 no. Acessado em: 30 de julho.

OLIVEIRA CD; BRAZ LT, SANTOS JM, OLIVEIRA, PR. 2007. Resistência de Capsicum spp. a Meloidogyne incognita. IN: CONGRESSO BRASILEIRO DE OLERICULTURA, 47. Resumos expandidos ... Disponível em http://www.abhorticultura. com.br. Acessado em 28 de fevereiro de 2008.

OSAVA M; GROGG P; FRANCO P. 2006. Extingue-se o brometo de metila no Brasil e em Cuba. Disponível em http://www.ambiente. sp.gov. br/prozonesp/noticias/230603.htm.
Acessado em 30 de julho.

SANTOS HS. 2001. Enxertia em plantas de pimentão (Capsicum annuum L.) no controle da murcha de Fitóftora (Phytophthora capsici) em ambiente protegido. Botucatu: UNESPFCA. 86p (Tese mestrado).

SANTOS HS; GOTO R. 2004. Enxertia em plantas de pimentão no controle da murcha de fitóftora em ambiente protegido. Horticultura Brasileira 22: 45-49.

SANTOS HS; GOTO R. 2005. Desempenho produtivo de plantas de pimentão enxertadas e não enxertadas. In: CONGRESSO BRASILEIRO DE OLERICULTURA, 45; CONGRESSO BRASILEIRO DE FLORICULTURA E PLANTAS ORNAMENTAIS, 15; CONGRESSO BRASILEIRO DE CULTURA DE TECIDOS DE PLANTAS, 2. Resumos... Fortaleza: ABH (CD-ROM).

THIES JA; FERY RL. 2006. Heat stability of root-knot nematode resistance in bell pepper. Disponível em http://www.epa.gov/ozone/ mbr/airc/ 1997/032 thies.pdf. Acessado em 30 de julho.

TRANI PE; PASSOS FA; AZEVEDO FILHO JA. 1997. Berinjela, jiló, pimenta-hortícola e pimentão. In: RAIJ B; CANTARELLA H; QUAGGIO JA; FURLANI AMC. Recomendação de adubação e calagem para o Estado de São Paulo. Campinas: Instituto Agronômico de Campinas. p.173. (Boletim Técnico, 100).

YAMAKAWA K. 1982. Use of rootstocks in solanaceous fruit-vegetable production in Japan. Japan Agricultural Research Quarterly 15: $175-179$. 